\title{
Diffusion-Weighted Imaging of Brain Metastasis from Lung Cancer: Correlation of MRI Parameters with the Histologic Type and Gene Mutation Status
}

\author{
(D)W.S. Jung, (DC.H. Park, (DC.-K. Hong, (D)S.H. Suh, and (DS.J. Ahn
}

\begin{abstract}
BACKGROUND AND PURPOSE: Development of noninvasive imaging biomarkers indicating the histology and the gene mutation status of brain metastasis from lung cancer is important. We aimed to investigate diffusion-weighted imaging parameters as predictors of the histology and gene mutations of brain metastasis from lung cancer.
\end{abstract}

MATERIALS AND METHODS: DWI data for 74 patients with brain metastasis from lung cancer were retrospectively reviewed. The patients were first grouped according to the primary tumor histology (adenocarcinoma, small-cell lung cancer, squamous cell carcinoma), and those with adenocarcinoma were further divided into epidermal growth factor receptor (EFGR) mutation-positive and wild type groups. Sex; age; number, size, and location of brain metastasis; DWI visual scores; the minimum ADC; and the normalized ADC ratio were compared among groups using $\chi^{2}$ and ANOVA. Multiple logistic regression analysis was performed to determine independent predictors of the EGFR mutation.

RESULTS: The minimum ADC was lower in the small-cell lung cancer group than in the other 2 groups, though the difference was not significant. Furthermore, minimum ADC and the normalized ADC ratio were significantly lower in the EGFR mutation-positive group than in the wild type group $(P=.021$ and .014 , respectively). Multivariate analysis revealed that minimum ADC and the normalized ADC ratio were independently associated with the EGFR mutation status $(P=.028$ and .021 , respectively).

CONCLUSIONS: Our results suggest that DWI parameters (minimum ADC and normalized ADC ratio) for the solid components of brain metastasis from lung cancer are not correlated with their histology, whereas they can predict the EGFR mutation status in brain metastasis from lung adenocarcinoma.

ABBREVIATIONS: $\mathrm{ADC}_{\min }=$ minimum $\mathrm{ADC} ; \mathrm{BM}=$ brain metastasis; $E G F R=$ epidermal growth factor receptor; $\mathrm{nADC}=$ normalized $\mathrm{ADC} ; \mathrm{NSCLC}=$ non-small-cell lung cancer; TKI = tyrosine kinase inhibitor

ung cancer is one of the leading causes of cancer-related deaths in Last Asia and the most frequent site of origin for brain metastasis (BM). ${ }^{1-4}$ Despite advances in systemic therapy and improvement in survival rates for patients with advanced lung cancer, BM remains an important cause of morbidity and mortality. ${ }^{1}$ Recently, many studies reported that compared with those with BM with wild type epidermal

Received June 26, 2017; accepted after revision September 7.

From the Departments of Radiology (W.S.J., C.H.P., S.H.S., S.J.A.) and Neurosurgery (C.-K.H.), Gangnam Severance Hospital, Yonsei University, College of Medicine, Seoul, Korea; and Department of Radiology (W.S.J.), Ajou University School of Medicine, Suwon, Korea.

This study was supported by a faculty research grant from Yonsei University College of Medicine (6-2016-0111) and by a National Research Foundation of Korea (NRF) grant funded by the Korea government (MSIP) (No.2017RIC1B5014927). The funder had no role in study design, data collection and analysis, decision to publish, or preparation of the manuscript.

Please address correspondence to Sung Jun Ahn, MD, PhD, Department of Radiology, Gangnam Severance Hospital, Yonsei University, College of Medicine, 211 Eonju-ro, Gangnam-gu, Seoul 135-720, Korea; e-mail: aahng77@yuhs.ac

http://dx.doi.org/10.3174/ajnr.A5516 growth factor receptor (EGFR), patients with lung cancer with BM having EGFR mutations, particularly those with non-small-cell lung cancer (NSCLC), had improved survival due to higher response rates to whole-brain radiation therapy and specific chemotherapy medications such as EGFR-associated tyrosine kinase inhibitors (TKIs). ${ }^{5-8}$

Development of noninvasive imaging biomarkers indicating the gene mutation status of BM from lung cancer is important because they would provide clinicians with strong evidence for making clinical decisions, aid in the early initiation of specific chemotherapy for patients with gene mutations, and, consequently, contribute to an improved prognosis. ${ }^{8}$

Diffusion-weighted MR imaging of the brain is based on the differential diffusion rates or the Brownian motion of water. It is an essential technique for diagnosing acute infarction in the brain because of its ability to detect cytotoxic edema caused by altered water diffusion secondary to cellular damage. DWI is also widely used for the assessment of tumor pathology in the field of neuro-oncology. ${ }^{9}$ Specifically, apparent diffusion coefficient values derived from DWI have been shown to correlate with tumor cellularity, glioma grade, 


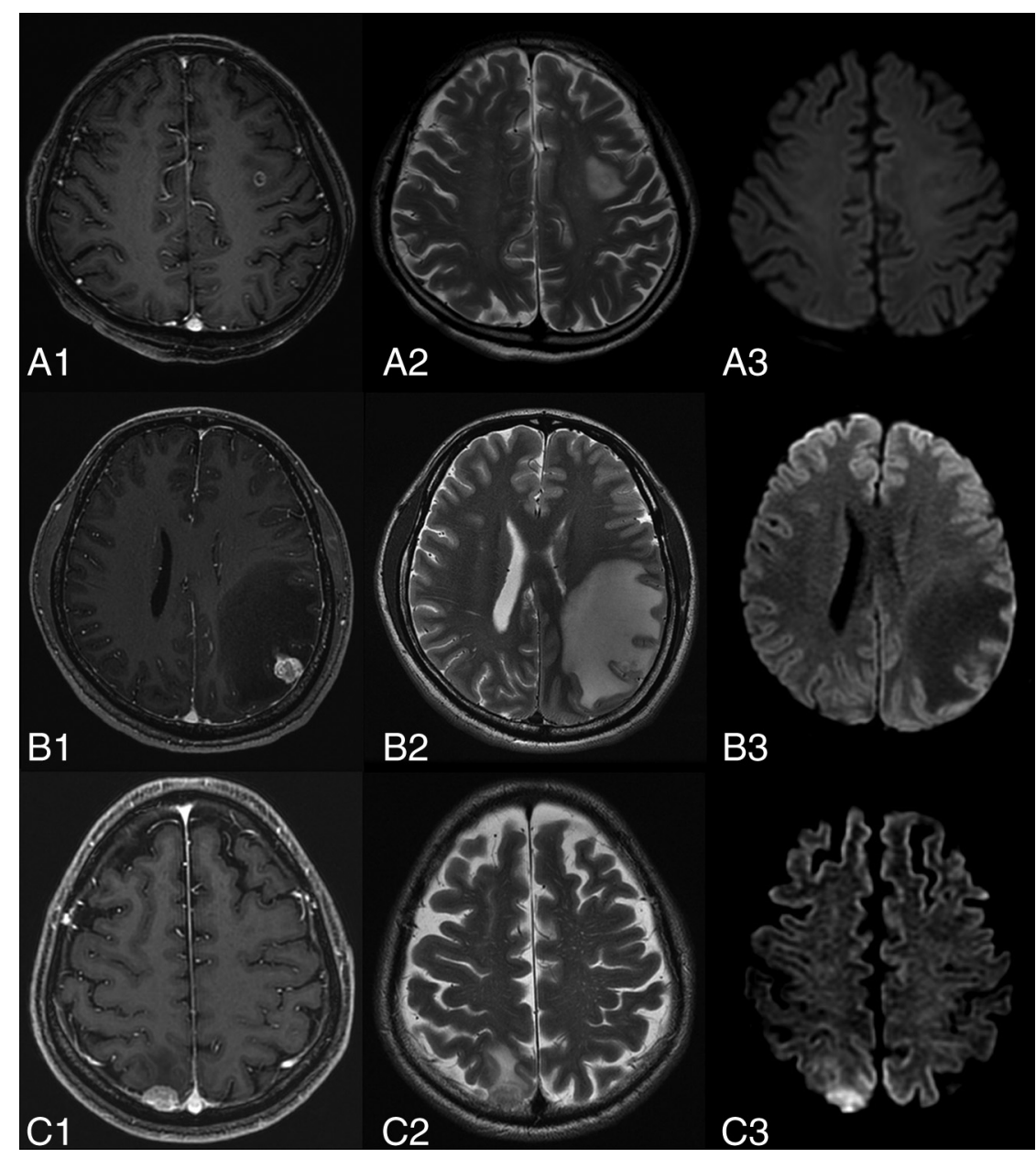

FIG 1. Representative MR images depicting visual scores based on diffusion-weighted imaging findings for brain metastasis from lung cancer. Contrast-enhanced T1-weighted images show an apparent enhanced tumor in the left frontal lobe (AT), left parietal lobe (BI), and right parietal lobe $(C 1)$. T2-weighted images $(A 2, B 2$, and $C 2)$ show varying degrees of peritumoral brain edema. $A 3$, $B M$ is not detectable on DWI $(A 3$, score $=1)$. $B 3$ and $C 3$, DWI images show iso-signal intensity $($ score $=2$ ) and high signal intensity $($ score $=3$ ), respectively, relative to the normal-appearing cortical gray matter.

and treatment response. ${ }^{9-13}$ Moreover, recent studies have shown that DWI parameters may differentiate the histology of BM from lung cancer. ${ }^{14,15}$ However, the association between DWI parameters and the gene mutation status has not been assessed for BM from lung cancer, to our knowledge.

We hypothesized that the molecular and genetic backgrounds of tumors affect signal intensity and ADC values of lung cancer $\mathrm{BM}$ on DWI. Therefore, we aimed to investigate DWI parameters as imaging biomarkers for prediction of the histologic type and gene mutation status of BM from lung cancer.

\section{MATERIALS AND METHODS \\ Patient Population}

We retrospectively reviewed data for 100 patients diagnosed with BM from lung cancer between January 2012 and April 2016. All patients had received a histopathologic diagnosis of lung cancer based on bronchoscopic, percutaneous needle-guided, or surgical biopsies and had undergone gene mutation studies. Accordingly, they were stratified into groups based on the histopathology of the lung cancer. Furthermore, patients with lung adenocarcinoma were divided according to the gene mutation status.

\section{MR Imaging Protocol}

\section{Image Evaluation}

We excluded patients with the following conditions: MR imaging evidence of intratumoral hemorrhage $(n=5)$, lesions that were too small for the measurement of ADC values $(n=12)$, leptomeningeal seeding metastasis $(n=6)$, and a history of chemotherapy or radiation therapy for $\mathrm{BM}(n=3)$. Eventually, 74 patients were included in this study. Approval for the use of clinical data was obtained from the internal review board of our institution (Gangnam Severance Hospital).

\section{Pathology and EGFR Mutation Analysis of Lung Cancer}

One experienced pathologist (Heae Surng Park, with 8 years of experience in pathology) evaluated the pathology and EGFR mutation status of the lung cancer. Genomic DNA was extracted from the lung cancer specimen, and EGFR tyrosine kinase exons 19, 20, and 21 and $V$-Ki-ras2 Kirsten rat sarcoma viral oncogene homolog (Kras) were amplified by a nested polymerase chain reaction using specific primers. Fluorescence in situ hybridization testing with anaplastic lymphoma kinase (Alk) breakapart probes was performed to detect rearrangements. The details of the sequencing procedure are described elsewhere. ${ }^{16,17}$ The presence of EGFR mutations was determined by the presence of deletions within exons 19 and 20 and L858R point mutations in exon 21 .

All patients were imaged with a 3T clinical MR imaging device (Discovery MR750, GE Healthcare, Milwaukee, Wisconsin; Achieva, Philips Healthcare, Best, the Netherlands). Our MR imaging protocol for BM included routine T2-weighted fast-spin-echo sequences (TR/TE, 5414/96 ms), axial fluid-attenuated inversion recovery sequences (TR/TE/TI, 4000/80/2000 ms), axial diffusion-weighted echo-planar sequences (TR/TE, 8000/65.6 ms; slice thickness/intersection gap, 4/1 mm; matrix size, $160 \times 160$; FOV, $240 \times 240 \mathrm{~mm} ; 3$ directions; $\mathrm{b}$-value $=0$ and $\left.1000 \mathrm{~s} / \mathrm{mm}^{2}\right)$, and contrast-enhanced $3 \mathrm{D}$ T1 fast-spoiled gradient-recalled sequences (TR/TE, 8.2/3.2 ms; flip angle, $12^{\circ}$; slice thickness, $1 \mathrm{~mm}$; matrix size, $256 \times 256$; FOV , $220 \times$ $220 \mathrm{~mm}$ ). Intravenous gadolinium-based contrast agent was used at a dose of $0.1 \mathrm{mmol} / \mathrm{kg}$ body weight. ADC values were automatically calculated by the operating console of the MR imaging device and displayed as corresponding ADC maps.

Two experienced neuroradiologists (S.H.S., with 12 years of experience in neuroimaging, and S.J.A., with 6 years of experience in 


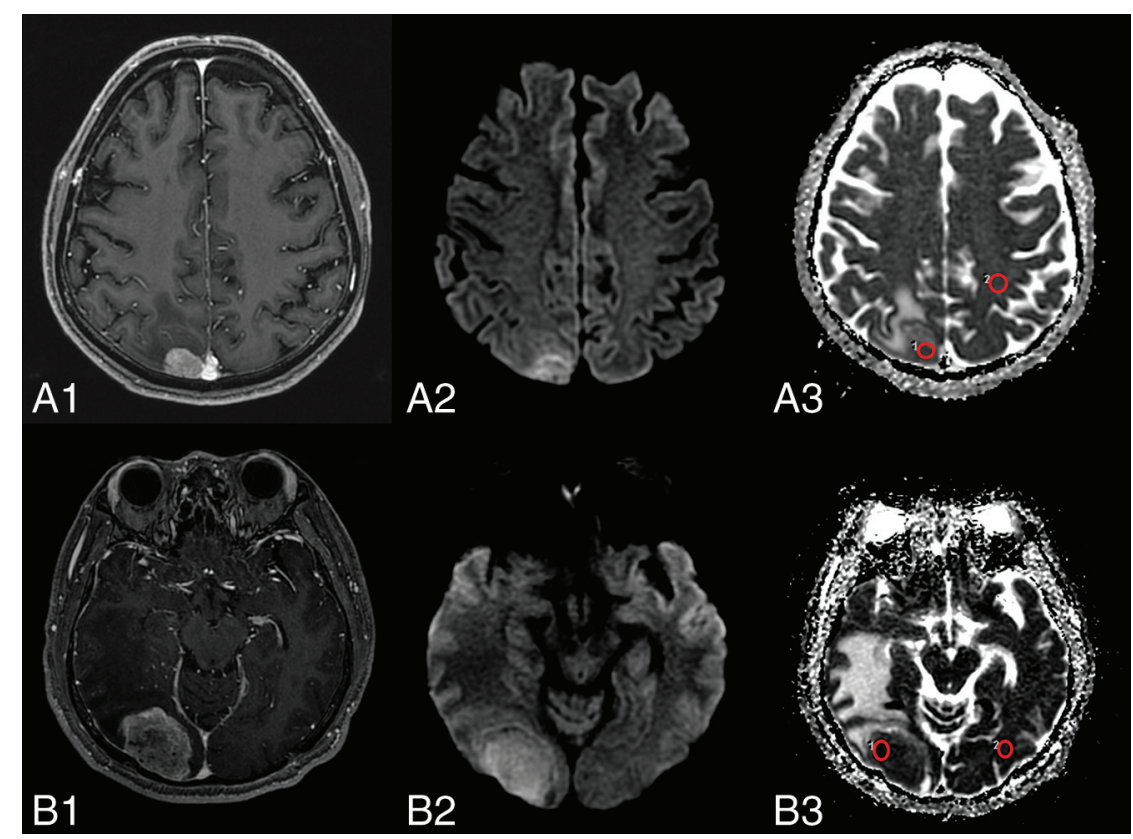

FIG 2. Representative images depicting the ROI within a tumor and the corresponding contralateral normal-appearing white matter for the calculation of apparent diffusion coefficient values for brain metastasis lesions stratified by the EGFR mutation status. $A 1$ and $B 1$, Contrast-enhanced T1-weighted images show contrast enhancement of the metastasis. $A 2$ and B2, Diffusionweighted images show mild-to-moderate high signal intensity in the contrast-enhanced areas. $A 3$ and $B 3, A D C$ map with ROls within the tumor and corresponding contralateral normal-appearing white matter. Al-A3, Wild type EGFR. BI-B3, EGFR mutation-positive.

neuroimaging) visually assessed the signal intensity on DWI in areas corresponding to the enhanced portion of the lesions on contrast-enhanced T1-weighted images; both were blinded to the clinical and pathologic information. If there were multiple brain lesions, the largest one, which reflected DWI findings for most BM lesions, was selected as the target lesion to increase the accuracy of the measurement. The lesions on DWI were visually scored as follows: 1, negative findings on DWI; 2, isointense relative to the normal-appearing cortical gray matter; and 3, hyperintense relative to the normal-appearing cortical gray matter (Fig 1).

The study coordinator (W.S.J.) marked circular ROIs (each area, $20 \mathrm{~mm}^{2}$ ) over the target lesion on the ADC map, avoiding cystic or necrotic parts. The minimum $\mathrm{ADC}\left(\mathrm{ADC}_{\text {min }}\right)$ value was calculated from these ROIs. The same method was applied to a corresponding site in the contralateral white matter judged as normal on both contrast-enhanced T1- and T2-weighted images. Then, to assess the objective difference between the ADC value for the tumor and for the contralateral normal area, the normalized $\mathrm{ADC}$ ( $\mathrm{nADC}$ ) ratio was calculated as the ratio of the $\mathrm{ADC}_{\text {min }}$ of the tumor divided by the $\mathrm{ADC}_{\text {min }}$ of the corresponding contralateral white matter area (Fig 2).

\section{Statistical Analysis}

All statistical analyses were performed with the statistical software SAS, Version 9.2 (SAS Institute, Cary, North Carolina), and MedCalc for Windows, Version 12.7.0 (MedCalc Software, Mariakerke, Belgium). The $\chi^{2}$ test and ANOVA were used to compare DWI visual scores, $\mathrm{ADC}_{\text {min }}$ values, the $\mathrm{nADC}$ ratio, the number and size of the BMs, and the presence of intratumoral necrosis or hemorrhage among the adenocarcinoma, squamous cell carcinoma, and small-cell lung carcinoma groups. Subgroup analysis according to the gene mutation status was also performed for the adenocarcinoma group. For multivariate analysis, a linear regression model was used to identify statistically significant variables. To investigate the interobserver reproducibility for DWI visual scores, we derived the intraclass correlation coefficient with a 2-way random model of absolute agreement.

\section{RESULTS}

Relationship between DWI Visual Scores and BM Histology and Mutation Status

In total, 74 patients (mean age, $64.19 \pm 10.76$ years; 50 men and 24 women) with BMs from lung cancer underwent DWI. Of these, 56 (75.67\%) were diagnosed with adenocarcinoma (group 1); 11 (14.86\%), with smallcell lung cancer (group 2); and 7 $(9.45 \%)$, with squamous cell carcinoma (group 3). Of the 56 adenocarcinomas, 12 were poorly differentiated, 2 were well-differentiated, and 1 was moderately differentiated adenocarcinoma. For the remaining 41 cases of adenocarcinoma, detailed pathologic results were not available.

The 56 patients with adenocarcinoma were subdivided according to the status of mutations in EGFR, Alk, and Kras. In total, 55 patients had been examined for the EGFR mutation status, with 26 having EGFR mutations and 29 having wild type EGFR. Among the patients with EGFR mutations, 13, 4, and 9 had mutations in exons 19,20 , and 21 , respectively. In addition, mutations were confirmed in 4 of 29 and 3 of 32 patients examined for Alk and Kras mutations, respectively.

Interobserver reproducibility for DWI visual scores was excellent (intraclass correlation coefficient, 0.972 ; 95\% confidence interval, $0.955-0.982 ; P<.001$ ). There was no significant difference in DWI visual scores among the 3 histologybased groups (Table 1) and between the 2 mutation-based groups (Table 2).

\section{Relationship between ADC Values and Histologic Type}

$\mathrm{ADC}_{\text {min }}$ and the $\mathrm{nADC}$ ratio were not significantly different among the small-cell lung cancer $\left(531.18 \pm 160.54 \times 10^{-6} \mathrm{~mm}^{2} / \mathrm{s}\right.$ and $0.88 \pm 0.2$, respectively), adenocarcinoma (623.38 \pm $163.07 \times 10^{-6} \mathrm{~mm}^{2} / \mathrm{s}$ and $1.04 \pm 0.28$, respectively), and squamous cell carcinoma $\left(682.14 \pm 182.07 \times 10^{-6} \mathrm{~mm}^{2} / \mathrm{s}\right.$ and $1.11 \pm$ 0.28 , respectively; $P=.131$ and 0.144 ) groups. Moreover, the location, size, and number of BMs and the presence of intratumoral hemorrhage or necrosis showed no significant differences among groups. The detailed patient characteristics are shown in Table 1 .

AJNR Am J Neuroradiol 39:273-79 Feb 2018 www.ajnr.org 
Table 1: Characteristics of BM among primary lung cancer groups

\begin{tabular}{|c|c|c|c|c|c|}
\hline & $\begin{array}{l}\text { Total } \\
(n=74)\end{array}$ & $\begin{array}{l}\text { Adenocarcinoma } \\
(n=56)\end{array}$ & $\begin{array}{l}\text { Small-Cell Lung } \\
\text { Cancer }(n=11)\end{array}$ & $\begin{array}{c}\text { Squamous Cell } \\
\text { Carcinoma }(n=7)\end{array}$ & $\begin{array}{c}P \\
\text { Value }\end{array}$ \\
\hline DWI visual score & & $1.87 \pm 0.76$ & $2.27 \pm 0.90$ & $1.85 \pm 0.69$ & .298 \\
\hline$A D C_{\min }\left(\times 10^{-6} \mathrm{~mm}^{2} / \mathrm{s}\right)$ & $615.23 \pm 166.83$ & $623.38 \pm 163.07$ & $531.18 \pm 160.54$ & $682.14 \pm 182.07$ & .131 \\
\hline nADC ratio & $1.02 \pm 0.28$ & $1.04 \pm 0.28$ & $0.88 \pm 0.2$ & $1.11 \pm 0.28$ & .144 \\
\hline Age (yr) & $64.19 \pm 10.76$ & $63.63 \pm 11.15$ & $68.09 \pm 9.14$ & $62.57 \pm 9.73$ & .420 \\
\hline Male sex & $50(67.57)$ & $36(64.29)$ & $9(81.82)$ & $5(71.43)$ & .587 \\
\hline Site of BM & & & & & .545 \\
\hline Anterior circulation- dominant ${ }^{a}$ & $25(33.78)$ & $21(37.5)$ & $2(18.18)$ & $2(28.57)$ & \\
\hline Posterior circulation-dominant ${ }^{b}$ & $11(14.86)$ & $7(12.5)$ & $2(18.18)$ & $2(28.57)$ & \\
\hline Even distribution & $38(51.35)$ & $28(50)^{\prime}$ & $7(63.64)$ & $3(42.86)$ & \\
\hline No. of BMs & & & & & .051 \\
\hline 1 & $18(24.32)$ & $16(28.57)$ & $0(0)$ & $2(28.57)$ & \\
\hline $1<\mathrm{BM}<10$ & $43(58.11)$ & $32(57.14)$ & $6(54.55)$ & $5(71.43)$ & \\
\hline$\geq 10$ & $13(17.57)$ & $8(14.29)$ & $5(45.45)$ & $0(0)$ & \\
\hline Target lesion size of BM & & & & & .367 \\
\hline$<10 \mathrm{~mm}$ & $31(41.89)$ & $22(39.29)$ & $7(63.64)$ & $2(28.57)$ & \\
\hline $10 \mathrm{~mm} \leq \mathrm{BM}<30 \mathrm{~mm}$ & $32(43.24)$ & $24(42.86)$ & $3(27.27)$ & $5(71.43)$ & \\
\hline$\geq 30 \mathrm{~mm}$ & $11(14.86)$ & $10(17.86)$ & $1(9.09)$ & $0(0)$ & \\
\hline Intratumoral necrosis & $32(43.24)$ & $21(37.5)$ & $6(54.55)$ & $5(71.43)$ & .160 \\
\hline Intratumoral hemorrhage & $15(20.27)$ & $11(19.64)$ & $3(27.27)$ & $1(14.29)$ & .882 \\
\hline
\end{tabular}

${ }^{a}$ BMs mainly located in the frontal, parietal, and temporal lobes.

b BMs mainly located in the occipital lobes, cerebellum, and brain stem.

Table 2: Comparison of $A D C_{\text {min }}$ values and normalized $A D C$ ratio according to gene mutation status in adenocarcinoma group

\begin{tabular}{lccc}
\hline & Wild Type & Mutation & $P$ Value \\
\hline EGFR & $29(52.7)$ & $26(47.3)$ & \\
$\mathrm{DWI}$ visual score & $1.92 \pm 0.77$ & $1.87 \pm 0.76$ & .179 \\
$\mathrm{ADC}$ min $\left(\times 10^{-6} \mathrm{~mm}^{2} / \mathrm{s}\right)$ & $674.55 \pm 182.78$ & $575.85 \pm 115.01$ & .021 \\
$\mathrm{nADC}$ ratio & $1.13 \pm 0.32$ & $0.95 \pm 0.19$ & .014 \\
Alk & $25(86.2)$ & $4(13.8)$ & \\
$\mathrm{DWI}$ visual score & $1.96 \pm 0.79$ & $2 \pm 1.15$ & .930 \\
$\mathrm{ADC}$ min $\left(\times 10^{-6} \mathrm{~mm}^{2} / \mathrm{s}\right)$ & $583.8 \pm 183.84$ & $562 \pm 159.12$ & .825 \\
$\mathrm{nADC}$ ratio & $1 \pm 0.34$ & $0.83 \pm 0.19$ & .328 \\
$\mathrm{Kras}_{\mathrm{DWI}}$ & $29(90.6)$ & $3(9.4)$ & \\
$\mathrm{ADC}$ (isual score & $1.82 \pm 0.77$ & $2.33 \pm 0.57$ & .274 \\
$\mathrm{nADC}$ ratio & $641.31 \pm 168.32$ & $631.45 \pm 161.74$ & .310 \\
& $1.08 \pm 0.31$ & $1.08 \pm 0.32$ & .926 \\
\hline
\end{tabular}

and wild type groups and between the Kras mutation-positive and wild type groups (Table 2).

Multivariate logistic regression analysis revealed that $\mathrm{ADC}_{\min }$ and the $\mathrm{nADC}$ ratio were independently associated with the EGFR mutation status (OR, 0.996; 95\% CI, 0.992-1.000; $P=.028$; and OR, 0.064; 95\% CI, 0.006-0.666; $P=.021$, respectively) after adjustment for sex; age; size, location, and number of BMs; presence of intratumoral necrosis or hemorrhage; and DWI visual scores. Specifically, $\mathrm{ADC}_{\text {min }}$ and the nADC ratio were significantly associated with exon 19 and/or 21 mutations (OR,

\section{Relationship between ADC Values and Gene Mutation Status}

$\mathrm{ADC}_{\text {min }}$ was significantly lower in the EGFR mutation-positive group than in the wild type group $\left(575.85 \pm 115.01 \times 10^{-6}\right.$ $\mathrm{mm}^{2} / \mathrm{s}$ versus $\left.674.55 \pm 182.78 \times 10^{-6} \mathrm{~mm}^{2} / \mathrm{s}, P=.021\right)$; similar results were obtained for the nADC ratio $(0.95 \pm 0.19$ versus $1.13 \pm 0.32, P=.014)$. However, there were no significant differences in the location, size, and number of BMs and the presence of necrosis or hemorrhage between groups (Table 2).

$\mathrm{ADC}_{\text {min }}$ and the $\mathrm{nADC}$ ratio also showed significant differences according to the following EGFR genotypes: exon 19 and/or 21 mutations $\left(n=22 ; 564.14 \pm 109.25 \times 10^{-6} \mathrm{~mm}^{2} / \mathrm{s}\right.$ and $0.93 \pm$ 0.17 , respectively), exon 20 mutations $(n=4 ; 640.25 \pm 141.90 \times$ $10^{-6} \mathrm{~mm}^{2} / \mathrm{s}$ and $1.05 \pm 0.28$, respectively), and wild type EGFR $\left(n=29 ; 674.55 \pm 182.78 \times 10^{-6} \mathrm{~mm}^{2} / \mathrm{s}\right.$ and $1.13 \pm 0.32$, respectively; $P=.049$ and .038). A post hoc analysis showed that $\mathrm{ADC}_{\text {min }}$ and the $\mathrm{nADC}$ ratio were significantly lower in the exon 19 and/or 21 mutation group than in the wild type group ( $P=$ .039 and 0.029 , respectively; Fig 3 ). There was no significant difference in the 2 parameters between the Alk mutation-positive
0.995; 95\% CI, 0.991-0.999; $P=.020$; and OR, 0.044; 95\% CI, $0.004-0.563 ; P=.016$, respectively; Table 3 ).

\section{DISCUSSION}

In the present study, we tested the hypothesis that the signal intensity of BM from lung cancer on DWI may be expressed differently according to the genetic background of the lesion. Our results indicated a significant association of $\mathrm{ADC}_{\min }$ and the $\mathrm{nADC}$ ratio with the EGFR mutation status and the location of the mutation. However, there was no association between the ADC parameters and the histologic type of the tumor.

A few previous studies have demonstrated opposing results for the relationship between the histologic type and DWI parameters for BM from lung cancer. Hayashida et $\mathrm{al}^{14}$ evaluated 26 brain metastatic lesions in patients with primary lung cancer and reported that small- and large-cell neuroendocrine carcinomas showed high signal intensity on DWI. Thus, they concluded that signal intensity on DWI can predict the histology of metastases. However, Duygulu et $\mathrm{al}^{15}$ evaluated 37 patients with BM from lung cancer and reported the absence of a correlation between 

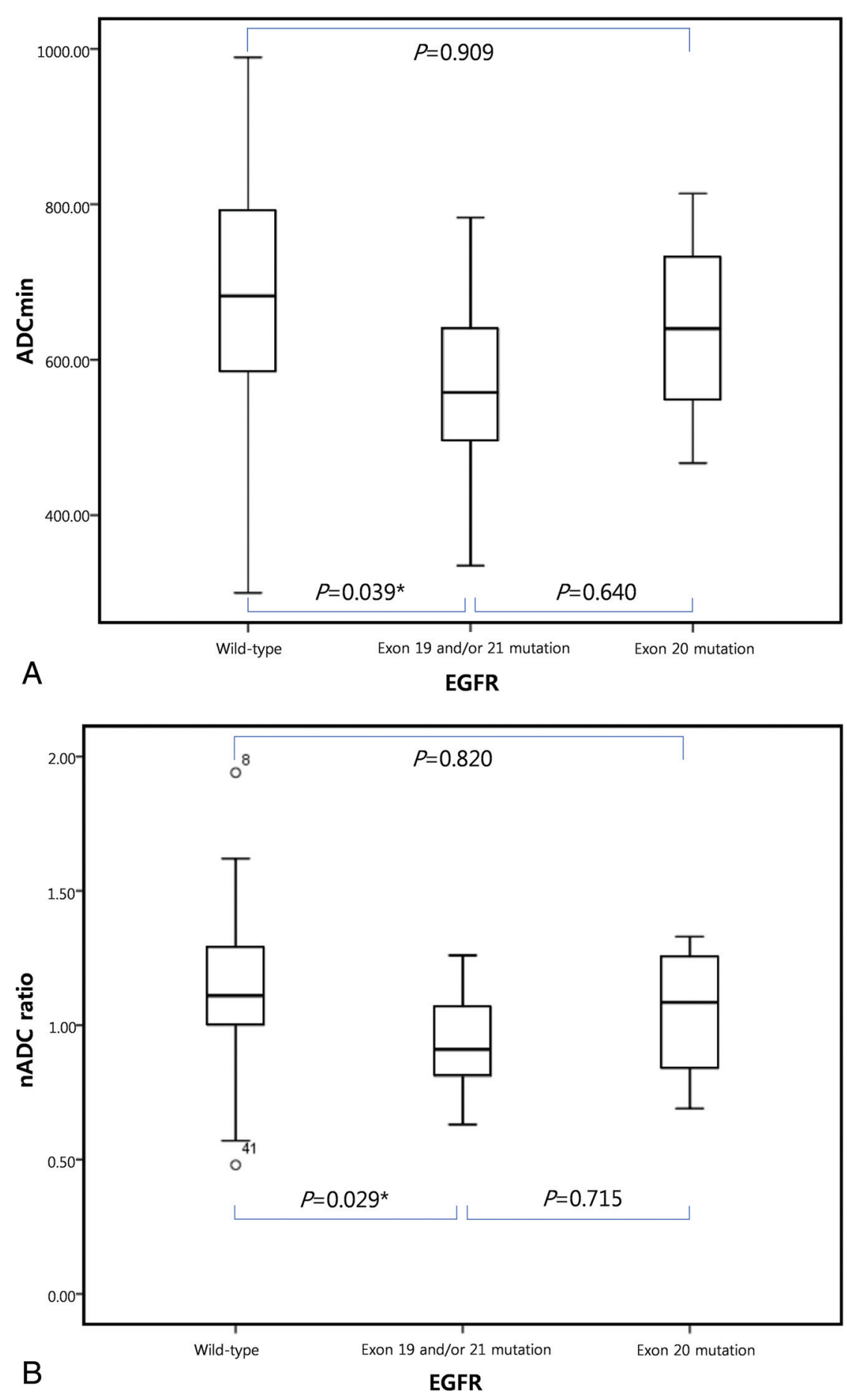

FIG 3. Boxplot for minimum apparent diffusion coefficient $(A)$ and normalized ADC ratio $(B)$ values for patients with lung adenocarcinoma with wild type EGFR, mutations in exon 19 and/or 21 , and mutations in exon 20. Asterisk indicates statistically significant.

restricted diffusion on DWI and the primary pathology. In the present study, we also found no correlation between DWI parameters and BM histology; we believe our results are more reliable because of the large sample size compared with those in the previous studies. However, a nonsignificant trend existed for lower $\mathrm{ADC}_{\min }$ and $\mathrm{nADC}$ in the small-cell lung cancer group, even compared with the adenocarcinoma EGFR mutation-positive group. In our results, most small-cell lung cancer cases $(8 / 11)$ showed lower ADC values $\left(<600 \times 10^{-6} \mathrm{~mm}^{2} / \mathrm{s}\right)$, while the mi- nority (3/11) showed higher ADC values ( $\geq 600 \times 10^{-6} \mathrm{~mm}^{2} / \mathrm{s}$ ). Two conflicting ADC values of small-cell lung cancer may explain the nonsignificant result of a lower ADC trend for small-cell lung cancer. We presume that there may be 2 different subtypes of small-cell lung cancer and would recommend further study.

EGFR is a transmembrane protein with cytoplasmic kinase activity that transduces important growth factor signaling from the extracellular milieu to the cell. ${ }^{18}$ For patients with advanced NSCLC, initial therapy with a TKI can lead to substantial therapeutic improvement and may be considered as an alternative treatment for $\mathrm{BM}$ in the future. ${ }^{8,17,19-21}$ Sensitive EGFR mutations are found in the first 4 exons (18-21) of the tyrosine kinase domain of EGFR, and the 2 major mutations are deletions in exon 19 and a single point mutation in exon 21 (L858R). ${ }^{22-24}$ Identification of exon 19 or 21 mutation is also a useful tool for the prediction of response to treatment with TKI. ${ }^{25-27}$ Also, several studies have demonstrated that the characteristics of $\mathrm{BM}$ are dependent on the EGFR genotype. The number of BM lesions was significantly higher in patients with EGFR-mutated NSCLC than in those with wild type NSCLC. Moreover, leptomeningeal metastases were more common in patients with EGFRmutated NSCLC. ${ }^{8}$ Tumors with exon 19 deletions reportedly showed a higher incidence of BM compared with tumors with exon 21 mutations. ${ }^{28}$

A previous study indicated that patients with NSCLC bearing exon 19 deletions exhibited a peculiar pattern of multiple, small brain metastases, similar to miliary BM. ${ }^{29}$ Another study showed that brain metastases with exon 21 mutations were more common in the caudate, cerebellum, and temporal lobe compared with those with exon 19 deletions. $^{30}$ Other characteristic molecular changes of non-small-cell lung cancer are a Kras mutation and Alk rearrangement. ${ }^{31,32}$ Patients who were Alk-positive and treated with the Alk TKI crizotinib in the second-line setting experienced improved progression-free survival compared with standard chemotherapy. ${ }^{33}$ Patients with NSCLC with Alk rearrangements have improved survival outcome after radiation therapy for BMs. ${ }^{34}$ On the contrary, there are currently no target therapy options for patients with the Kras mutation. 


\begin{tabular}{|c|c|c|c|c|}
\hline \multirow[b]{2}{*}{ Predictors } & \multicolumn{2}{|c|}{$\begin{array}{l}\text { EGFR Mutation } \\
\text { (Exon } 19+20+21)\end{array}$} & \multicolumn{2}{|c|}{$\begin{array}{l}\text { EGFR Mutation } \\
\text { (Exon } 19+21)\end{array}$} \\
\hline & OR $(95 \% \mathrm{Cl})$ & $P$ Value & OR $(95 \% \mathrm{CI})$ & $P$ Value \\
\hline Female sex & $1.630(0.539-4.927)$ & .387 & $1.538(0.483-4.898)$ & .466 \\
\hline Age, per 1-yr increase & $0.975(0.928-1.024)$ & .307 & $0.972(0.923-1.024)$ & .282 \\
\hline \multicolumn{5}{|l|}{ Site of BM } \\
\hline Anterior circulation-dominant ${ }^{\mathrm{a}}$ & Reference & & Reference & \\
\hline Posterior circulation-dominant ${ }^{b}$ & $0.750(0.132-4.250)$ & .745 & $0.833(0.145-4.781)$ & .837 \\
\hline Even distribution & $0.867(0.275-2.734)$ & .807 & $0.741(0.222-2.471)$ & .625 \\
\hline \multicolumn{5}{|l|}{ No. of BM } \\
\hline 1 & Reference & & Reference & \\
\hline $1<\mathrm{BM}<10$ & $1.765(0.491-6.337)$ & .383 & $1.765(0.446-6.979)$ & .418 \\
\hline$\geq 10$ & $6.000(0.873-41.214)$ & .068 & $7.500(1.039-54.116)$ & .045 \\
\hline \multicolumn{5}{|l|}{ Target lesion size of BM } \\
\hline$<10 \mathrm{~mm}$ & Reference & & Reference & \\
\hline $10 \mathrm{~mm} \leq \mathrm{BM}<30 \mathrm{~mm}$ & $1.015(0.318-3.243)$ & .979 & $0.923(0.275-3.102)$ & .897 \\
\hline$\geq 30 \mathrm{~mm}$ & $1.500(0.315-7.135)$ & .61 & $1.333(0.260-6.828)$ & .729 \\
\hline Intratumoral necrosis & $1.188(0.395-3.569)$ & .759 & $0.887(0.273-2.884)$ & .841 \\
\hline Intratumoral hemorrhage & $1.440(0.382-5.428)$ & .59 & $1.412(0.353-5.649)$ & .625 \\
\hline Diffusion visual scoring & $1.630(0.680-2.601)$ & .199 & $1.514(0.722-2.974)$ & .274 \\
\hline$A D C_{\min }$ & $0.996(0.992-1.000)$ & .028 & 0.995 (0.991-0.999) & .020 \\
\hline nADC ratio & $0.064(0.006-0.666)$ & .021 & $0.044(0.004-0.563)$ & .016 \\
\hline
\end{tabular}

a BMs mainly located in the frontal, parietal, and temporal lobes.

${ }^{\mathrm{b}}$ BMs mainly located in the occipital lobes, cerebellum, and brain stem.

Gene expression analysis is based on invasive tissue sampling and can be associated with sampling errors; therefore, the development of imaging markers that reflect the gene mutation status is important. ${ }^{35}$ Our findings demonstrated that low ADC values for BM from lung adenocarcinoma are associated with a high possibility of an EGFR mutation, particularly in exons 19 and 21. Such patients are expected to respond well to noninvasive TKI treatment, and clinicians can plan this treatment accordingly if the mutation status is known. Moreover, Huang et $\mathrm{al}^{13}$ recently reported that $\mathrm{ADC}_{\text {min }}$ has the potential to predict and monitor the response of primary CNS lymphoma to chemotherapy. Therefore, through further study, we can apply serial ADC values to predict the response of BM from lung adenocarcinoma with EGFR mutations to TKI treatment.

Our study had several limitations. First, grades of lung cancer pathology (well, moderately, or poorly differentiated) in adenocarcinoma were not considered, which can affect the results of DWI parameters. ${ }^{14}$ Second, the genetic testing was performed with samples obtained from the lungs because brain metastases were diagnosed using brain MR imaging rather than histologic confirmation. Further study is necessary, in which tissues are obtained directly from the brain lesion, revealing the molecular biologic characteristics of the BMs more reliably.

\section{CONCLUSIONS}

We demonstrated that there is no correlation between ADC values $\left(\mathrm{ADC}_{\min }\right.$ or $\mathrm{nADC}$ ratio) of the solid components of the BM from lung cancer and their histologic type. However, the EGFR gene mutation status of BM from lung adenocarcinoma can be predicted using ADC values. A further prospective, large-scale cohort study is needed to demonstrate the relationship between gene mutation status and ADC values.

\section{ACKNOWLEDGMENTS}

All authors appreciate Heae Surng Park for her assistance in pathologic review of this study.

\section{REFERENCES}

1. Nayak L, Lee EQ, Wen PY. Epidemiology of brain metastases. Curr Oncol Rep 2012;14:48-54 CrossRef Medline

2. Jemal A, Tiwari RC, Murray T, et al; American Cancer Society. Cancer statistics, 2004. CA Cancer J Clin 2004;54:8-29 CrossRef Medline

3. Shin HR, Ahn YO, Bae JM, et al. Cancer incidence in Korea. Cancer Res Treat 2002;34:405-08 CrossRef Medline

4. Won YJ, Sung J, Jung KW, et al. Nationwide cancer incidence in Korea, 2003-2005. Cancer Res Treat 2009;41:122-31 CrossRef Medline

5. Lynch TJ, Bell DW, Sordella R, et al. Activating mutations in the epidermal growth factor receptor underlying responsiveness of non-small-cell lung cancer to gefitinib. N Engl J Med 2004;350: 2129-39 CrossRef Medline

6. Mok TS, Wu YL, Thongprasert S, et al. Gefitinib or carboplatin-paclitaxel in pulmonary adenocarcinoma. N Engl J Med 2009;361:947-57 CrossRef Medline

7. Johnson ML, Sima CS, Chaft J, et al. Association of KRAS and EGFR mutations with survival in patients with advanced lung adenocarcinomas. Cancer 2013;119:356-62 CrossRef Medline

8. Eichler AF, Kahle KT, Wang DL, et al. EGFR mutation status and survival after diagnosis of brain metastasis in nonsmall cell lung cancer. Neuro Oncol 2010;12:1193-99 CrossRef Medline

9. Wieduwilt MJ, Valles F, Issa S, et al. Immunochemotherapy with intensive consolidation for primary CNS lymphoma: a pilot study and prognostic assessment by diffusion-weighted MRI. Cancer Res Treat 2012;18:1146-55 CrossRef Medline

10. Lee EJ, Lee SK, Agid R, et al. Preoperative grading of presumptive low-grade astrocytomas on MR imaging: diagnostic value of minimum apparent diffusion coefficient. AJNR Am J Neuroradiol 2008; 29:1872-77 CrossRef Medline

11. Guo AC, Cummings TJ, Dash RC, et al. Lymphomas and high-grade astrocytomas: comparison of water diffusibility and histologic characteristics. Radiology 2002;224:177-83 CrossRef Medline

12. Lee KC, Moffat BA, Schott AF, et al. Prospective early response im- 
aging biomarker for neoadjuvant breast cancer chemotherapy. Cancer Res Treat 2007;13:443-50 Medline

13. Huang WY, Wen JB, Wu G, et al. Diffusion-weighted imaging for predicting and monitoring primary central nervous system lymphoma treatment response. AJNR Am J Neuroradiol 2016;37: 2010-18 CrossRef Medline

14. Hayashida Y, Hirai T, Morishita S, et al. Diffusion-weighted imaging of metastatic brain tumors: comparison with histologic type and tumor cellularity. AJNR Am J Neuroradiol 2006;27:1419-25 Medline

15. Duygulu G, Ovali GY, Calli C, et al. Intracerebral metastasis showing restricted diffusion: correlation with histopathologic findings. Eur J Radiol 2010;74:117-20 CrossRef Medline

16. Han SW, Kim TY, Hwang PG, et al. Predictive and prognostic impact of epidermal growth factor receptor mutation in non-smallcell lung cancer patients treated with gefitinib. J Clin Oncol 2005;23: 2493-501 CrossRef Medline

17. Cho BC, Im CK, Park MS, et al. Phase II study of erlotinib in advanced non-small-cell lung cancer after failure of gefitinib. J Clin Oncol 2007;25:2528-33 CrossRef Medline

18. da Cunha Santos G, Shepherd FA, Tsao MS. EGFR mutations and lung cancer. Annu Rev Pathol 2011;6:49-69 CrossRef Medline

19. Lee YJ, Choi HJ, Kim SK, et al. Frequent central nervous system failure after clinical benefit with epidermal growth factor receptor tyrosine kinase inhibitors in Korean patients with nonsmall-cell lung cancer. Cancer 2010;116:1336-43 CrossRef Medline

20. Matsumoto $S$, Takahashi K, Iwakawa R, et al. Frequent EGFR mutations in brain metastases of lung adenocarcinoma. Int J Cancer 2006; 119:1491-94 CrossRef Medline

21. Omuro AM, Kris MG, Miller VA, et al. High incidence of disease recurrence in the brain and leptomeninges in patients with nonsmall cell lung carcinoma after response to gefitinib. Cancer 2005;103: 2344-48 CrossRef Medline

22. Gazdar AF. Activating and resistance mutations of EGFR in nonsmall-cell lung cancer: role in clinical response to EGFR tyrosine kinase inhibitors. Oncogene 2009;28(suppl 1):S24-31 CrossRef Medline

23. Greulich $\mathrm{H}$, Chen TH, Feng W, et al. Oncogenic transformation by inhibitor-sensitive and -resistant EGFR mutants. PLoS Med 2005;2: e313 CrossRef Medline

24. Ichihara S, Toyooka S, Fujiwara Y, et al. The impact of epidermal growth factor receptor gene status on gefitinib-treated Japanese patients with non-small-cell lung cancer. Int J Cancer 2007;120: 1239-47 CrossRef Medline
25. Jackman DM, Yeap BY, Sequist LV, et al. Exon 19 deletion mutations of epidermal growth factor receptor are associated with prolonged survival in non-small cell lung cancer patients treated with gefitinib or erlotinib. Clin Cancer Res 2006;12:3908-14 CrossRef Medline

26. Carey KD, Garton AJ, Romero MS, et al. Kinetic analysis of epidermal growth factor receptor somatic mutant proteins shows increased sensitivity to the epidermal growth factor receptor tyrosine kinase inhibitor, erlotinib. Cancer Res 2006;66:8163-71 CrossRef Medline

27. Mulloy R, Ferrand A, Kim Y, et al. Epidermal growth factor receptor mutants from human lung cancers exhibit enhanced catalytic activity and increased sensitivity to gefitinib. Cancer Res 2007;67: 2325-30 CrossRef Medline

28. Heon S, Yeap BY, Britt GJ, et al. Development of central nervous system metastases in patients with advanced non-small cell lung cancer and somatic EGFR mutations treated with gefitinib or erlotinib. Clin Cancer Res 2010;16:5873-82 CrossRef Medline

29. Sekine A, Kato T, Hagiwara E, et al. Metastatic brain tumors from non-small cell lung cancer with EGFR mutations: distinguishing influence of exon 19 deletion on radiographic features. Lung Cancer 2012;77:64-69 CrossRef Medline

30. Takano K, Kinoshita M, Takagaki M, et al. Different spatial distributions of brain metastases from lung cancer by histological subtype and mutation status of epidermal growth factor receptor. Neuro Oncol 2016;18:716-24 CrossRef Medline

31. Slebos RJ, Kibbelaar RE, Dalesio O, et al. K-ras oncogene activation as a prognostic marker in adenocarcinoma of the lung. $N$ Engl J Med 1990;323:561-65 CrossRef Medline

32. Soda M, Choi YL, Enomoto M, et al. Identification of the transforming EML4-ALK fusion gene in non-small-cell lung cancer. Nature 2007;448:561-66 CrossRef Medline

33. Shaw AT, Kim DW, Nakagawa K, et al. Crizotinib versus chemotherapy in advanced ALK-positive lung cancer. N Engl J Med 2013;368: 2385-94 CrossRef Medline

34. Mak KS, Gainor JF, Niemierko A, et al. Significance of targeted therapy and genetic alterations in EGFR, ALK, or KRAS on survival in patients with non-small cell lung cancer treated with radiotherapy for brain metastases. Neuro Oncol 2015;17:296-302 CrossRef Medline

35. Jamshidi N, Diehn M, Bredel M, et al. Illuminating radiogenomic characteristics of glioblastoma multiforme through integration of MR imaging, messenger RNA expression, and DNA copy number variation. Radiology 2014;270:1-2 CrossRef Medline 